\title{
PEMBEBANAN TUNGGAL MODEL CAKAR AYAM MODIFIKASI (CAM) POLA SEGIEMPAT PADA VARIASI JARAK MENGGUNAKAN METODE ELEMEN HINGGA
}

\author{
Andani Rias Sandi $\mathrm{S}^{1, \mathrm{a})}$, Bambang Setiawan ${ }^{2, \mathrm{~b})}$, Noegroho Djarwanti ${ }^{2, \mathrm{c}}$ \\ 1) Mahasiswa Fakultas Teknik, Prodi Teknik Sipil, Universitas Sebelas Maret \\ 2) Staff Fakultas Teknik, Prodi Teknik Sipil, Universitas Sebelas Maret \\ a)andanisandi@gmail.com \\ b)bbstw88@yahoo.co.id \\ c) noegroho di@yahoo.com \\ Jl. Ir. Sutami 36A, Surakarta 57126; Telp. 0271-634524
}

\begin{abstract}
Abstrack
Soft soil has a low carrying capacity and can easily decline. High water content will cause a difficulty to construct buildings on the soft soil. One of the way that can be done to overcome this problem is by using modified cakar ayam foundation (CAM). This research was conducted to determine the effect of variations in claw distance with quadrilateral pattern on deflection, maximum moment and latitude force caused by single load using finite element method (FEM). V ariations in the distance between claws used in this study are $2.25 \mathrm{~m}, 2.50 \mathrm{~m}$, and $2.75 \mathrm{~m}$. Plates with claws will also be compared with clawless plates. The results of deflection values of plate with cakar and without cakar have a difference of $7.41 \%$ to $18.23 \%$, with a maximum deflection value on the system with cakar occurs at the load on the edge of the pavement of $-0.537 \mathrm{~mm}$. The value of the deflection occur at a variation of a distance of $2.50 \mathrm{~m}$. The most effective distance variation in modified chicken claw modeling is $2.25 \mathrm{~m}$ between claws.
\end{abstract}

Keywords : CAM, FEM, deflection

\begin{abstract}
Abstrak
Tanah lunak memiliki daya dukung rendah dan mudah mengalami penurunan. Kadar air yang tinggi akan menyebabkan sulitnya melakukan pembangunan di atas tanah lunak. Cara yang dapat dilakukan untuk mengatasi permasalahan ini salah satunya yaitu dengan menggunakan pondasi cakar ayam modifikasi (CAM). Penelitian ini dilakukan untuk mengetahui pengaruh variasi jarak antar cakar dengan pola segiempat terhadap defleksi, momen maksimum dan gaya lintang yang ditimbulkan akibat beban tunggal dengan menggunakan metode elemen hingga (MEH). Variasi jarak antar cakar yang digunakan dalam penelitian ini yaitu $2,25 \mathrm{~m}, 2,50 \mathrm{~m}$, dan $2,75 \mathrm{~m}$. Pelat dengan cakar juga akan dibandingkan dengan pelat tanpa cakar. Hasil nilai defleksi dengan cakar dan tanpa cakar memiliki selisih 7,41\% hingga 18,23\%, dengan nilai defleksi maksimum pada sistem dengan cakar terjadi pada beban di tepi ujung perkerasan sebesar $-0,537 \mathrm{~mm}$. Nilai defleksi terbesar terjadi pada variasi jarak 2,50 m. Variasi jarak yang paling efektif pada pemodelan cakar ayam modifikasi yaitu pada jarak antar cakar 2,25 m.
\end{abstract}

Kata kunci : CAM, MEH, defleksi

\section{PENDAHULUAN}

Tanah lunak merupakan tanah yang memiliki daya dukung rendah dan mudah mengalami penurunan. Kadar air yang tinggi akan menyebabkan sulitnya melakukan pembangunan di atas tanah lunak. Perkerasan jalan di Indonesia banyak yang harus dibangun di atas tanah lunak. Subgrade yang terbentuk dari tanah lunak akan menyebabkan kerusakan-kerusakan pada jalan raya.

Cara yang dapat dilakukan untuk mengatasi permasalahan ini salah satunya yaitu dengan menggunakan pondasi cakar ayam. Pondasi cakar ayam ditemukan pada tahun 1961 oleh Sediyatmo yang digunakan untuk bangunan menara listrik tegangan tinggi di daerah Ancol yang tanahnya rawa-rawa. Seiring perkembangan zaman pondasi cakar ayam mengalami modifikasi sehingga penggunaannya dapat digunakan pada bangunan gedung bahkan landasan pacu di 
bandara. Sistem Cakar Ayam Modifikasi menggunakan pipa galvanized anti karat yang terbuat dari baja ringan dengan berat sekitar $35 \mathrm{~kg}$, tebal 1,4 mm, diameter berkisar 0,6 $\mathrm{m}$ hingga $0,8 \mathrm{~m}$ dan panjang $1 \mathrm{~m}$ hingga 1,2 $\mathrm{m}$. Sistem Cakar Ayam sangat cocok digunakan pada perkerasan jalan di atas tanah lunak. Fungsi dari pondasi cakar ayam modifikasi ini adalah untuk menambah daya dukung tanah pada tanah lunak.

Penelitian ini dilakukan untuk mengetahui pengaruh variasi jarak antar cakar dengan pola segiempat terhadap defleksi, momen maksimum dan gaya lintang yang ditimbulkan akibat beban tunggal. Pengamatan yang dilakukan yaitu menggunakan Metode Elemen Hingga (MEH). Pada penelitian ini akan dapat mengetahui variasi yang paling efektif untuk diterapkan pada cakar ayam modifikasi.

\section{LANDASAN TEORI}

\section{Tanah Lunak}

Tanah lunak merupakan jenis tanah yang memiliki kuat geser rendah sehingga apabila beban yang melintas diatas tanah terlalu besar maka tanah akan mudah mengalami pergeseran. Selain itu tanah lunak juga memiliki kompresibilitas yang tinggi sehingga mudah mengalami penurunan. Tanah lunak juga mempunyai daya dukung tanah yang rendah, sehingga perlu dilakukan perbaikan tanah sebelum tanah dijadikan subgrade / tanah dasar pada bangunan atau jalan agar tanah lunak tersebut memenuhi syarat sebagai lapisan tanah dasar. Salah satu tipe tanah yang termasuk dalam jenis tanah lunak yaitu lempung lunak.

Tanah lunak mengandung mineral-mineral lempung dan mengandung kadar air yang tinggi. Indonesia tidak lepas dari tanah lunak karena tanah lunak di Indonesia menempati area $>20$ juta hektar atau $>10 \%$ dari tanah daratan di Indonesia dan itupun tersebar di daerah kota besar dan pusat pertumbuhan ekonomi negara (panduan Geoteknik 1, 2001).

\section{Cakar Ayam Modifikasi}

Sistem cakar ayam modifikasi merupakan pengembangan dari sistem cakar ayam Sediyatmo pada tahun 1961. Pada sistem cakar ayam konvensional terdiri dari pelat beton bertulang dengan tebal 10 hingga $17 \mathrm{~cm}$ dan pipa-pipa cakar (beton) berdiameter $120 \mathrm{~cm}$, tebal $8 \mathrm{~cm}$, dan panjang pipa 150 hingga $200 \mathrm{~cm}$ yang tertanam pada lapisan subgrade. Pada bagian bawah pelat beton juga terdapat lapisan lean concrete setebal $\pm 10 \mathrm{~cm}$ dan lapisan sirtu setebal $\pm 30 \mathrm{~cm}$ yang berfungsi sebagai perkerasan sementara selama masa pelaksanaan dan agar permukaan tanah dasar tetap rata sehingga pelat beton dapat dibuat di atasnya.

Perubahan yang dilakukan pada cakar ayam modifikasi yaitu penggunaan material beton pada cakar diganti dengan material baja yang dilapisi dengan bahan pelindung anti karat. Bagian tepi dari sistem CAM dilengkapi dengan pelat penutup tepi vertikal dengan tebal 10 hingga $12 \mathrm{~cm}$ dan tinggi 40 hingga $50 \mathrm{~cm}$. Pelat penutup tepi ini disebut dengan koperan. Koperan berfungsi sebagai perkuatan tepi, dan mencegah pumping tanah dasar akibat beban kendaraan.

Dalam perancangan sistem cakar ayam Sedyatmo menyebutkan bahwa pelat yang melendut akibat beban akan dilawan oleh momen perlawanan cakar akibat tanah pasif di sekitar cakar, namun asumsi tersebut dianggap tidak tepat karena saat terjadi pembebanan tanah tidak dalam kondisi runtuh atau pasif. Hardiyatmo dkk mengusulkan penggunaan koefisien subgrade horizontal $\left(k_{b}\right)$ dalam menentukan tanah lateral di sekitar cakar. Analisis elemen hingga yang digunakan Suhendro (1996) dilakukan dengan memvariasikan nilai $k_{b}$, dengan nilai yaitu $k_{b}=10 k_{v}$. 


\section{Muatan Sumbu Terberat}

Muatan sumbu adalah jumlah tekanan roda dari satu sumbu kendaran terhadap jalan, kemudian beban didistribusikan ke pondasi jalan. Pengendalian beban berlebih dapat dilakukan dengan konsep Muatan Sumbu Terberat. Muatan Sumbu Terberat (MST) adalah beban gandar maksimum yang diijinkan pada jalan raya. Muatan Sumbu Terberat yang diterapkan oleh Balai Geoteknik Jalan (BGJ), Departemen Pekerjaan Umum Republik Indonesia, untuk perancangan perkerasan kaku adalah sebesar 10 ton $(100 \mathrm{kN})$, namun masih diberikan toleransi sebesar $90 \%$ sehingga menjadi 19 ton $(190 \mathrm{kN})$.

\section{METODE PENELITIAN}

\section{Data Geometri Cakar Ayam}

$\begin{array}{lll}\text { Lebar Jalan } & : 7,25 & \mathrm{~m} \\ \text { Tebal Jalan } & : 0,15 & \mathrm{~m} \\ \text { Tinggi Cakar } & : 1,20 & \mathrm{~m} \\ \text { Diameter Cakar } & : 0,80 & \mathrm{~m} \\ \text { Tebal Cakar } & : 1,40 & \mathrm{~mm} \\ \text { Tinggi Kooperan } & : 0,50 & \mathrm{~m} \\ \text { Pola Cakar } & : \text { Segiempat }\end{array}$

\section{Tipikal Layout CAM Bidang XY}

Pada penelitian ini pola yang dipakai dalam sistem Cakar Ayam Modifikasi adalah pola segiempat dengan 3 jarak antar cakar yang berbeda, yaitu $2,25 \mathrm{~m}, 2,50 \mathrm{~m}$, dan $2,75 \mathrm{~m}$.

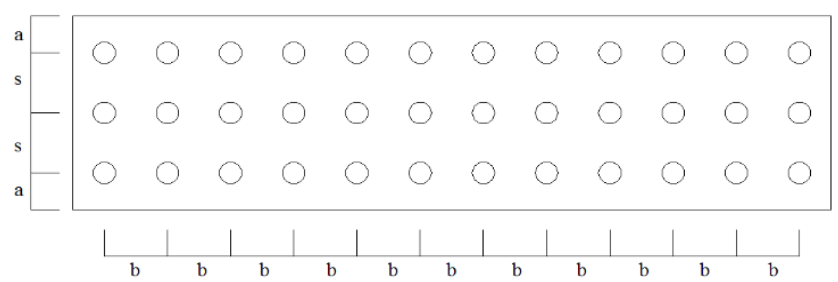

Gambar 1 Tipikal detail jarak antar cakar pada sistem CAM

Tabel 1 Detail Jarak antar Cakar

\begin{tabular}{cccc} 
Jarak antar Cakar $(\mathbf{m})$ & $\mathbf{a}(\mathbf{m})$ & $\mathbf{b}(\mathbf{m})$ & $\mathbf{s}(\mathbf{m})$ \\
\hline $\mathbf{2 , 2 5}$ & 1,375 & 2,25 & 2,25 \\
\hline $\mathbf{2 , 5 0}$ & 1,125 & 2,5 & 2,5 \\
\hline $\mathbf{2 , 7 5}$ & 0,875 & 2,75 & 2,75 \\
\hline
\end{tabular}

Nilai a akan semakin mengecil apabila jarak antar cakar semakin membesar, karena yang menjadi pusat adalah tengah perkerasan, sehingga cakar pada tengah perkerasan jaraknya tidak berubah.

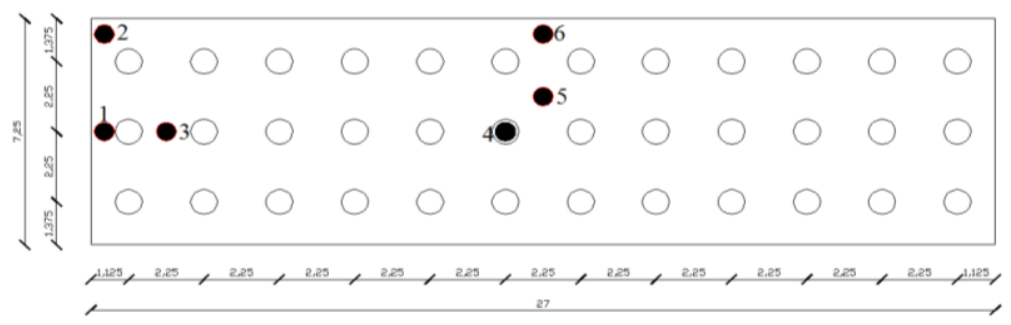

Gambar 2 Contoh Peletakan beban pada layout Sistem CAM dengan jarak antar cakar 2,25 m 
Posisi beban terletak pada 6 posisi yaitu di antara dua cakar, di tengah cakar, di antara empat cakar, dan di tepi perkerasan.

\section{Data Tanah dan Pembebanan}

Tanah yang digunakan dalam penelitian ini adalah tanah lunak dengan data sekunder yang diambil dari penelitian Setiawan (2015). Pembebanan penelitian ini menggunakan beban gandar Setiawan (2015) rencana sebesar 10 ton $(100 \mathrm{kN})$ pada bidang kontak $30 \mathrm{~cm}$.

\section{HASIL DAN PEMBAHASAN}

Rekapiulasi nilai defleksi potongan memanjang dengan analisis MEH menggunakan program SAP 2000 pada Tabel 2 adalah berikut :

Tabel 2 Rekapitulasi hasil defleksi berdasarkan posisi beban

\begin{tabular}{|c|c|c|c|c|c|c|c|}
\hline \multirow{2}{*}{\multicolumn{2}{|c|}{ Posisi Beban }} & \multicolumn{5}{|c|}{ Hasil Lendutan (mm) } & \multirow{3}{*}{$\begin{array}{c}\text { Selisih } \\
(\%)\end{array}$} \\
\hline & & \multirow{2}{*}{$\begin{array}{l}\text { Variasi } \\
\text { Tanpa } \\
\text { Cakar }\end{array}$} & \multicolumn{3}{|c|}{ Variasi Jarak Cakar } & \multirow{2}{*}{$\begin{array}{l}\text { Defleksi } \\
\text { Terbesar }\end{array}$} & \\
\hline & & & $\begin{array}{c}2,25 \\
\mathrm{~m}\end{array}$ & $2,50 \mathrm{~m}$ & $2,75 \mathrm{~m}$ & & \\
\hline \multirow[t]{3}{*}{$\begin{array}{c}\text { Di Pinggir } \\
\text { Ujung Pelat }\end{array}$} & $\begin{array}{c}\text { Titik } \\
1\end{array}$ & $-0,451$ & $\begin{array}{c}- \\
0,322\end{array}$ & $-0,379$ & $-0,332$ & $-0,379$ & 15,96 \\
\hline & $\begin{array}{c}\text { Titik } \\
2\end{array}$ & $-0,58$ & $\begin{array}{c}- \\
0,473\end{array}$ & $-0,537$ & $-0,441$ & $-0,537$ & 7,41 \\
\hline & $\begin{array}{c}\text { Titik } \\
10\end{array}$ & $-0,203$ & 0,169 & $-0,181$ & $-0,172$ & $-0,181$ & 10,83 \\
\hline Di As Pelat & $\begin{array}{c}\text { Titik } \\
7\end{array}$ & $-0,2$ & $\begin{array}{c}- \\
0,163\end{array}$ & $-0,167$ & $-0,17$ & $-0,17$ & 15,00 \\
\hline $\begin{array}{c}\text { Di antara } 2 \\
\text { Cakar }\end{array}$ & $\begin{array}{c}\text { Titik } \\
6\end{array}$ & $-0,203$ & $\begin{array}{c}- \\
0,152\end{array}$ & $-0,16$ & $-0,166$ & $-0,166$ & 18,23 \\
\hline $\begin{array}{c}\text { Di antara } 4 \\
\text { cakar }\end{array}$ & $\begin{array}{c}\text { Titik } \\
9\end{array}$ & $-0,198$ & 0,155 & $-0,166$ & $-0,175$ & $-0,175$ & 11,62 \\
\hline
\end{tabular}

Keterangan :

: Nilai defleksi maksimum

Berdasarkan Tabel 2 dihasilkan beberapa hal yaitu bahwa defleksi terbesar yang terjadi yaitu pada posisi pembebanan di ujung sisi pinggir perkerasan dengan jarak antar cakar 2,5 m sebesar $0,537 \mathrm{~mm}$ pada Titik 2 dan defleksi terkecil yang terjadi pada posisi beban di antara 2 cakar cakar (Titik 6) dengan jarak antar cakar 2,25 m yaitu sebesar 0,152 $\mathrm{mm}$. Defleksi yang terjadi yaitu dipengaruhi oleh jarak antar beban terhadap cakar terdekat, semakin jauh letak posisi beban dengan cakar maka semakin besar defleksi yang terjadi. Posisi pembebanan dan jarak antar cakar yang semakin melebar akan menghasilkan nilai defleksi yang maksimum.

Jarak antar cakar juga mempengaruhi besar kecilnya defleksi, didapat dari hasil bahwa semakin jauh jarak antar cakarnya semakin besar defleksi yang terjadi contohnya defleksi terbesar yang jarak antar cakarnya 2,75 m berada pada 3 titik dari 6 titik yang ada, sisanya berada pada 3 titik posisi beban dengan jarak antar cakar 2,50 m ketika jarak posisi beban dengan cakar berdekatan. Hal ini karena cakar akan bekerja secara kelompok dalam mereduksi defleksi yang terjadi, namun besarnya perlawanan atau yang dominan adalah cakar yang terdekat dengan posisi beban. Besar 
kecilnya defleksi juga bergantung juga pada posisi beban yang berada di pinggir maupun di tengah pelat.

1. Beban di titik 1

Hasil defleksi pada beban titik 1 disajikan dalam bentuk grafik seperti Gambar 3.
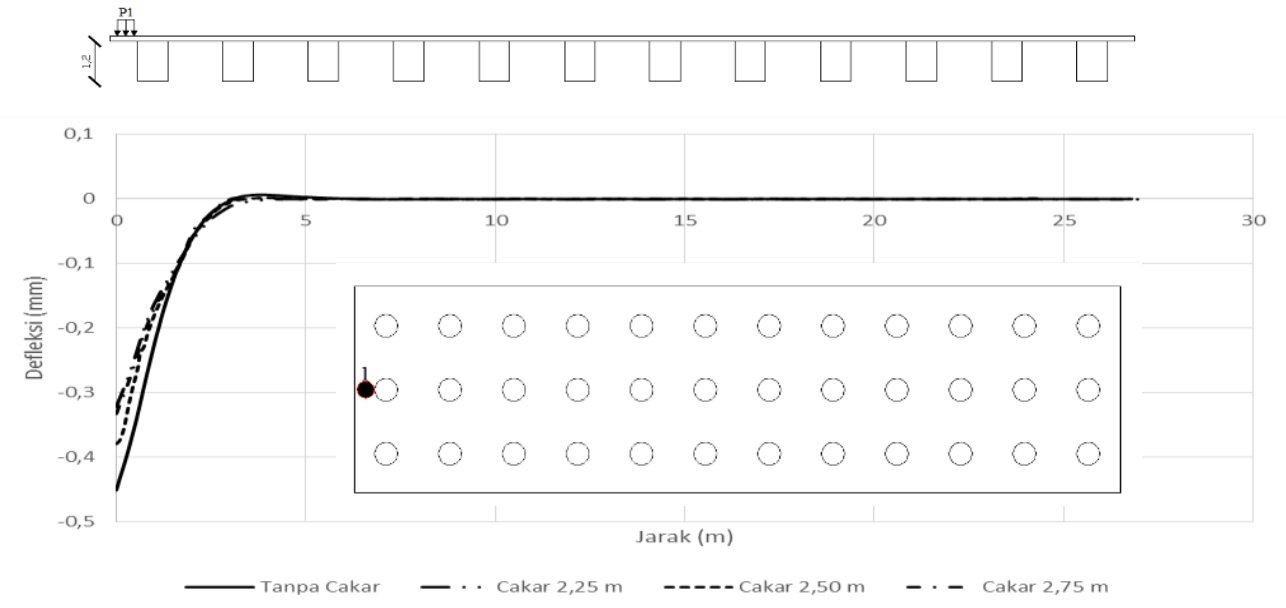

Gambar 3 Defleksi pada titik beban 1

Hasil perancangan model CAM dengan beban di tepi perkerasan menghasilkan defleksi yang besar. Gambar 3 menunjukkan nilai maksimum defleksi pada pelat tanpa cakar yaitu $-0,451 \mathrm{~mm}$, sedangkan pelat dengan cakar pada 3 variasi jarak yang berbeda nilai defleksi maksimum yaitu pada variasi 2,5 $\mathrm{m}$ dengan nilai $-0,379 \mathrm{~mm}$. Hasil tersebut membuktikan bahwa pelat dengan cakar memiliki defleksi yang lebih kecil daripada pelat tanpa cakar dengan selisih 0,072 $\mathrm{mm}$ atau sebesar 15,96 \% dari pelat tanpa cakar. Menunjukan sistem CAM lebih baik dalam mereduksi defleksi, cakar dalam CAM dapat menambah gaya perlawan terhadap defleksi dibanding dengan pelat tanpa cakar.

2. Beban di titik 2

Hasil defleksi pada beban titik 2 disajikan dalam bentuk grafik seperti Gambar 4.

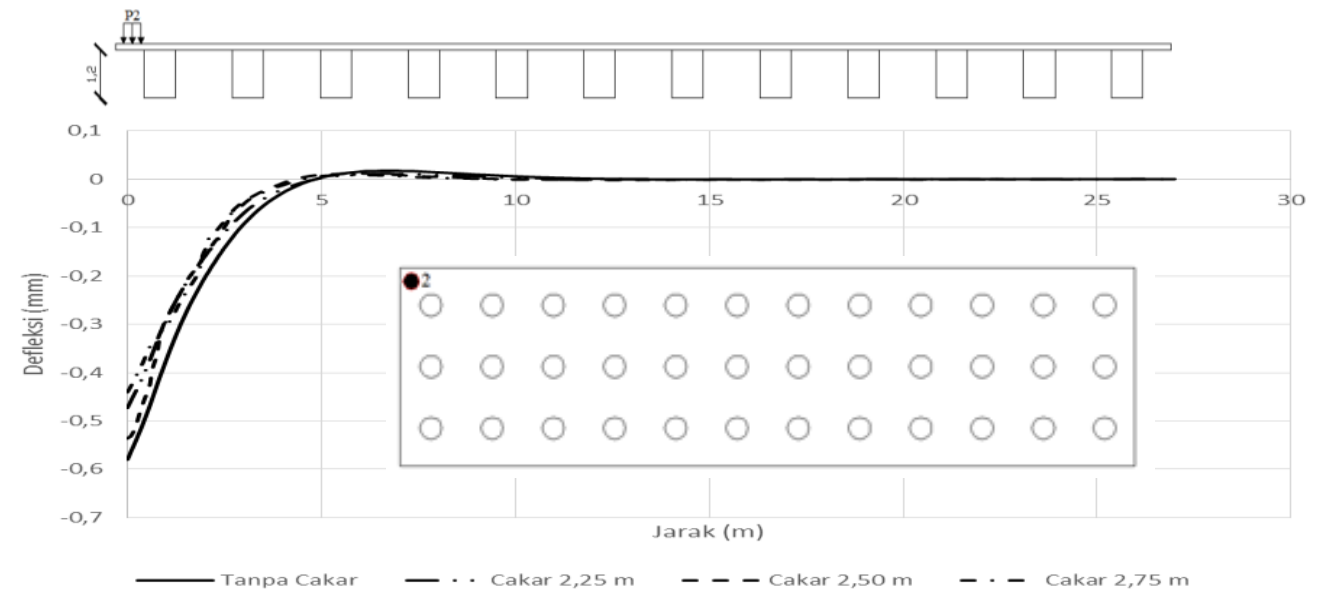

Gambar 4 Defleksi pada titik beban 2 
Pada Gambar 4 diperoleh nilai maksimum defleksi pada pelat tanpa cakar yaitu -0,580 mm, sedangkan pelat dengan cakar pada 3 variasi jarak yang berbeda nilai defleksi maksimum yaitu pada variasi 2,5 $\mathrm{m}$ dengan nilai $-0,537 \mathrm{~mm}$. Hasil tersebut membuktikan bahwa pelat dengan cakar memiliki defleksi yang lebih kecil daripada pelat tanpa cakar dengan selisih 0,043 $\mathrm{mm}$ atau sebesar 7,41\% dari pelat tanpa cakar.

3. Beban di titik 3

Hasil defleksi pada beban titik 3 disajikan dalam bentuk grafik seperti Gambar 5.

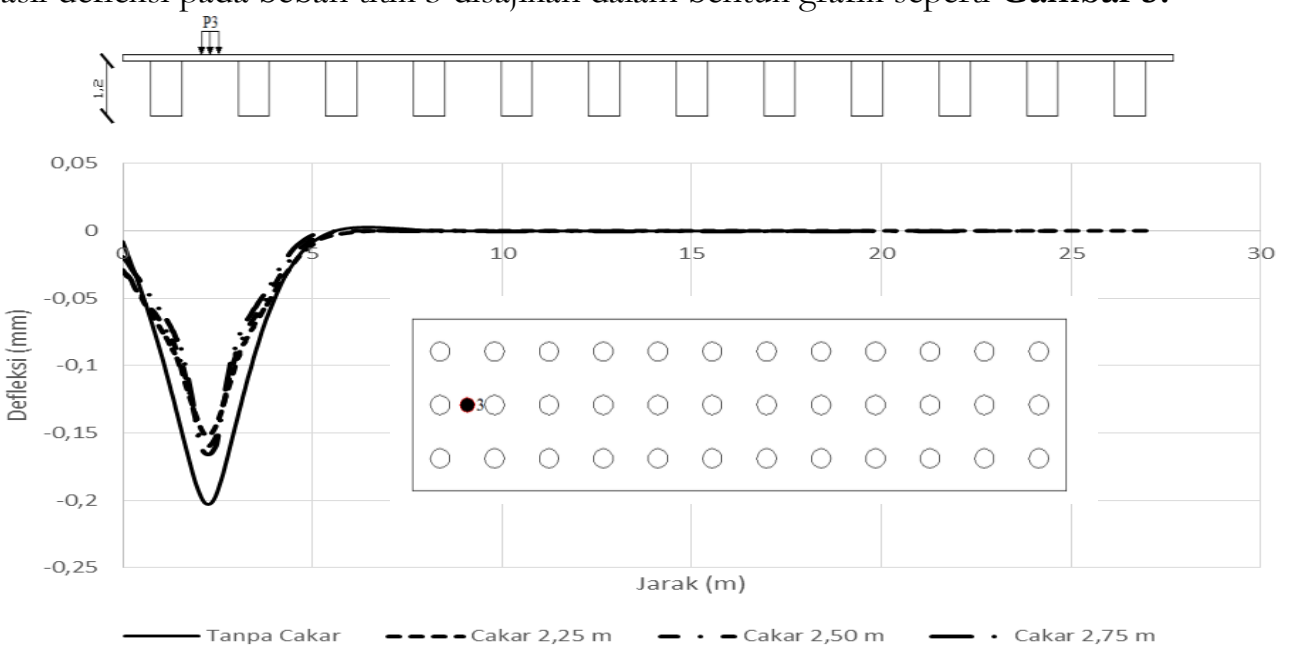

Gambar 5 Defleksi pada titik beban 3

Pada Gambar 5 diperoleh nilai maksimum defleksi pada pelat tanpa cakar yaitu -0,203 mm, sedangkan pelat dengan cakar pada 3 variasi jarak yang berbeda nilai defleksi maksimum yaitu pada variasi $2,75 \mathrm{~m}$ dengan nilai $-0,166 \mathrm{~mm}$. Hasil tersebut membuktikan bahwa pelat dengan cakar memiliki defleksi yang lebih kecil dari pada pelat tanpa cakar dengan selisih $0,037 \mathrm{~mm}$ atau sebesar 18,23 \% dari pelat tanpa cakar. Dengan hasil tersebut menjelaskan bahwa cakar mempengaruhi defleksi pada pelat.

4. Beban di titik 4

Hasil defleksi pada beban titik 4 disajikan dalam bentuk grafik seperti Gambar 6.

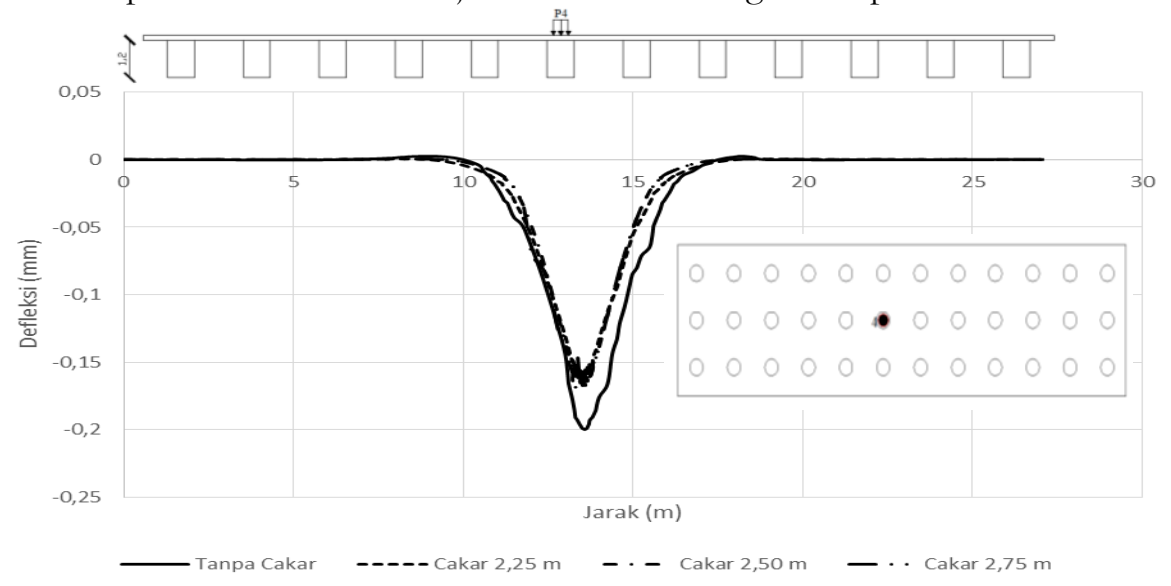

Gambar 6 Defleksi pada titik beban 4 
Pada Gambar 6 diperoleh nilai maksimum defleksi pada pelat tanpa cakar yaitu $-0,2 \mathrm{~mm}$, sedangkan pelat de ngan cakar pada 3 variasi jarak yang berbeda nilai defleksi maksimum yaitu pada variasi 2,75 $\mathrm{m}$ dengan nilai $-0,17 \mathrm{~mm}$. Hasil tersebut membuktikan bahwa pelat dengan cakar memiliki defleksi yang lebih kecil daripada pelat tanpa cakar dengan selisih 0,03 $\mathrm{mm}$ atau sebesar $15 \%$ dari pelat tanpa cakar. Beban yang berada pada tengah cakar yang berada pada tepi perkerasan dibandingkan dengan beban yang diletakkan pada tengah cakar di area tengah perkerasan memiliki nilai defleksi besar, di karenakan posisi beban yang semakin tepi akan semakin besar nilai defleksinya.

\section{Beban di titik 5}

Hasil defleksi pada beban titik 5 disajikan dalam bentuk grafik seperti Gambar 7.

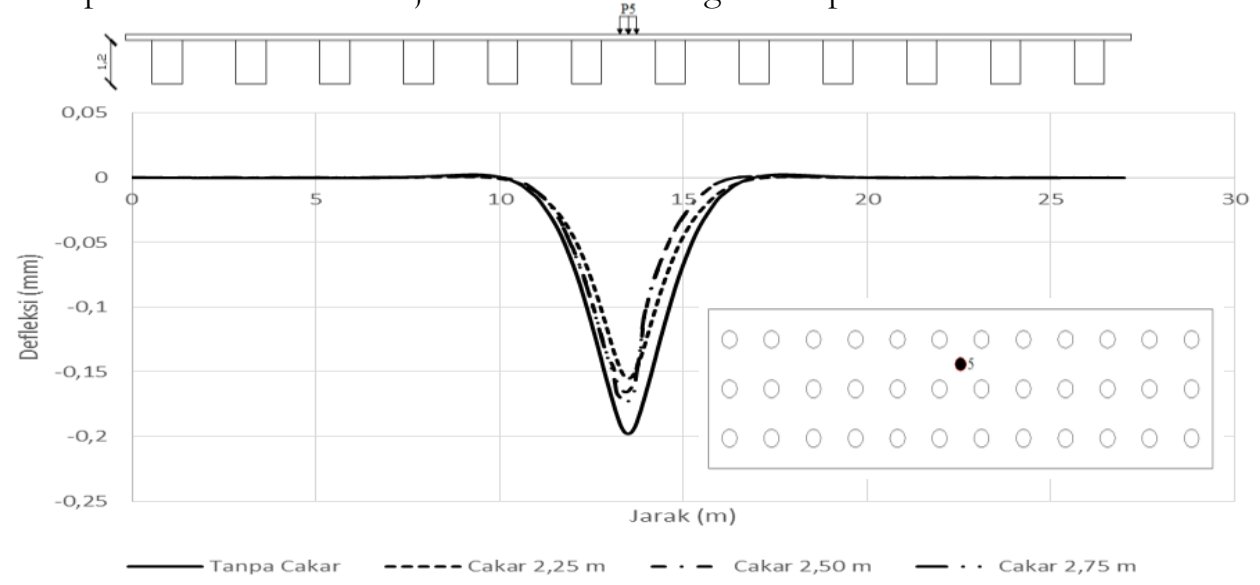

Gambar 7 Defleksi pada titik beban 5

Pada Gambar 7 diperoleh nilai maksimum defleksi pada pelat tanpa cakar yaitu -0,198 mm, sedangkan pelat dengan cakar pada 3 variasi jarak yang berbeda nilai defleksi maksimum yaitu pada variasi $2,75 \mathrm{~m}$ dengan nilai $-0,175 \mathrm{~mm}$. Hasil tersebut membuktikan bahwa pelat dengan cakar memiliki defleksi yang lebih kecil dari pada pelat tanpa cakar dengan selisih $0,023 \mathrm{~mm}$ atau sebesar $11,62 \%$ dari pelat tanpa cakar.

6. Beban di titik 6

Hasil defleksi pada beban titik 6 disajikan dalam bentuk grafik seperti Gambar 8.

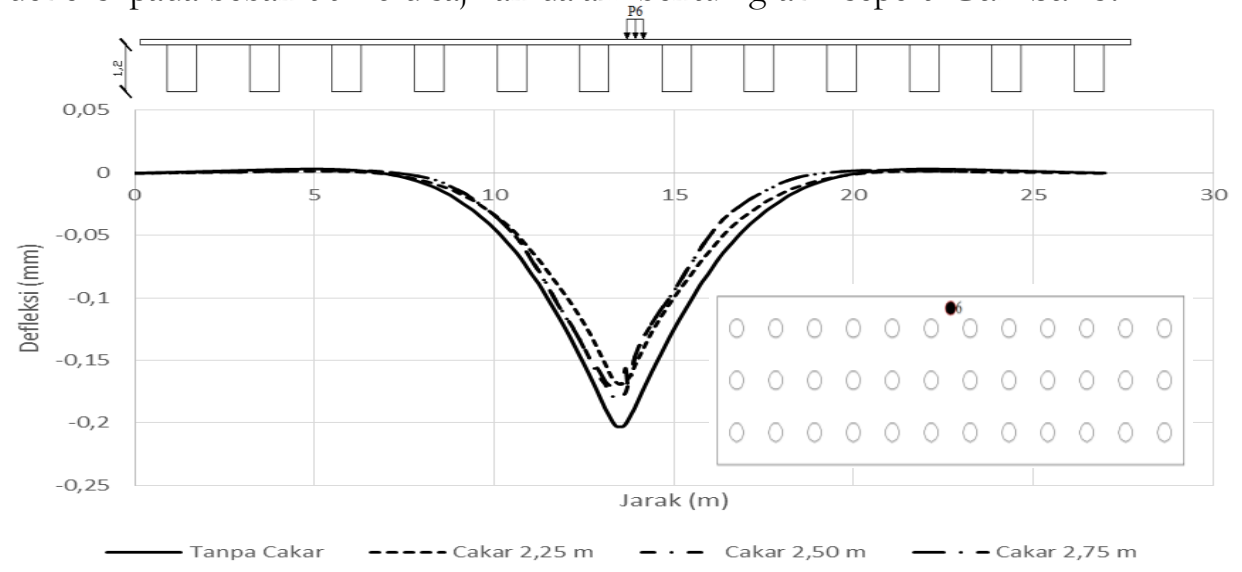

Gambar 8 Defleksi pada titik beban 6 
Pada Gambar 8 diperoleh nilai maksimum defleksi pada pelat tanpa cakar yaitu -0,203 mm, sedangkan pelat dengan cakar pada 3 variasi jarak yang berbeda nilai defleksi maksimum yaitu pada variasi $2,50 \mathrm{~m}$ dengan nilai $-0,181 \mathrm{~mm}$. Hasil tersebut membuktikan bahwa pelat dengan cakar memiliki defleksi yang lebih kecil daripada pelat tanpa cakar dengan selisih 0,022 $\mathrm{mm}$ atau sebesar 10,83\% dari pelat tanpa cakar. Dengan hasil tersebut menjelaskan bahwa cakar mempengaruhi defleksi pada pelat.

\section{Kesimpulan}

Berdasarkan analisis yang telah dilakukan, maka dapat disimpulkan bahwa :

1. Defleksi pada sistem CAM memiliki nilai yang lebih kecil dibandingkan dengan tanpa cakar dengan selisih 7,41\% hingga 18,23\%

2. Defleksi maksimum pada sistem CAM terjadi pada beban di tepi ujung perkerasan (titik 2) variasi $2,50 \mathrm{~m}$ sebesar $-0,537 \mathrm{~mm}$, sedangkan defleksi minimum terjadi pada beban di antara 2 cakar (titik 3) variasi 2,25 $\mathrm{m}$ sebesar $-0,152 \mathrm{~mm}$

3. Defleksi terbesar terjadi pada variasi jarak $2,50 \mathrm{~m}$

4. Posisi perletakan beban berpengaruh terhadap hasil analisis, beban yang diletakkan di tepi perkerasan akan menyebabkan nilai defleksi yang lebih besar daripada beban yang diletakkan di tengah perkerasan

\section{REKOMENDASI}

1. Perlu dilakukan pengujian skala kecil untuk membuktikan hasil analisis pada SAP2000 agar memperoleh hasil yang lebih akurat

2. Pengujian dengan variasi lain seperti dimensi, tebal cakar, tebal pelat pada sistem CAM dan parameter-paremeter lainnya untuk melihat perilaku Sistem CAM secara lebih luas.

\section{REFERENSI}

Hardiyatmo, H. C, 2014, Perancangan Sistem Cakar Ayam Modifikasi untuk Perkerasan Jalan Raya, Gajah Mada University Press, Yogyakarta.

Anggraini, F., 2008, Pengaruh Tinggi dan Pola Susunan Cakar Terbadap Perilaku Pelat Sistem Cakar Ayam Akibat Pengembangan dan Pembebanan (Tanah Dasar Campuran LempungBentonite), Tugas Akhir, Universitas Gajah Mada, Yogyakarta.

Firdiansyah, A., 2008, Pengaruh Tinggi dan Pola Susunan Cakar Terhadap Perilaku Pelat Sistem Cakar Ayam Akibat Pengembangan dan Pembebanan (Tanah Dasar Campuran LempungBentonite), Tugas Akhir, Universitas Gajah Mada, Yogyakarta.

Putra, H. G., 2007, Perilaku Lendutan Sistem Fondasi Cakar ayam Terhadap Pengembangan Tanah (Model Sistem Cakar Ayam dari Pelat Baja), Tugas Akhir, Universitas Gajah Mada, Yogyakarta.

Muhu, H., L., Y., 2007, Kajian Lendutan pada Sistem Cakar Ayam akibat Variasi Lebar Pelat Model Sistem Cakar Ayam dari Pelat Baja), Tugas Akhir, Universitas Gajah Mada, Yogyakarta.

Firdiansyah, A., 2009, Evaluasi Dimensi Sistem Cakar Ayam Akibat Pengaruh Variasi Beban dan Kondisi Tanah, Tesis, Universitas Gajah Mada, Yogyakarta.

Setiawan, B., 2015, Perilaku Sistem Cakar Ayam Modifikasi pada Tanah Ekspansif, Desertasi, Universitas Gajah Mada, Yogyakarta. 